\title{
OF BROKEN SEALS AND BROKEN PROMISES: Attributing Intention at the IAEA
}

\section{ANNA WEICHSELBRAUN \\ University of Vienna}

(Di) https:/ / orcid.org/0000-0002-3705-9968

In August 2005, workers at a uranium-conversion facility in Isfahan, Iran, cut metal seals from equipment and began feeding uranium ore concentrate (commonly known as yellowcake) into the production line to create uranium hexafluoride (UF6), which could then be enriched to produce nuclear fuel. The sealsthree-quarter-inch metal buttons - had been placed there by International Atomic Energy Agency (IAEA) inspectors just a few months earlier as part of a process of negotiations with the United Kingdom, France, and Germany to limit Iran's nuclear program. The IAEA had begun to increasingly scrutinize Iran's nuclear activities in 2002, when satellite imagery revealed that Iran was constructing two nuclear facilities without having notified the organization. ${ }^{1}$

The seals - technical artifacts inspectors use to monitor a state's nuclear commitments - temporarily suspended Iran's ability to produce uranium fuel. Placed at strategic points throughout a facility on vault doors, storage cabinets, and reactor lids, seals provide inspectors with information about the integrity of a sealed containment. The seals voluntarily placed at these facilities by Iran indicated the state's goodwill during the talks with the other powers, and their removal was widely interpreted as a sign of Iranian defiance. Mere days after Iran had notified the agency and removed the seals, the diplomats of the IAEA's Board of Governors 


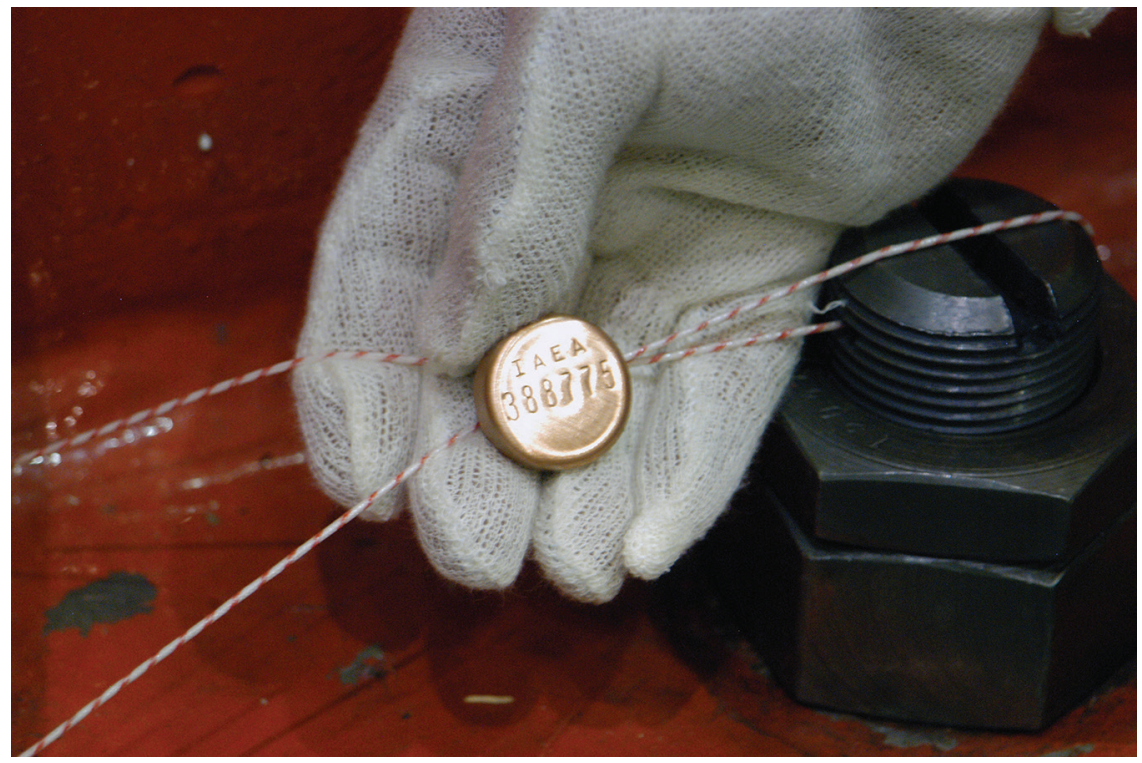

Figure 1. IAEA metal seal. Photo by Dean Calma/IAEA.

held an emergency meeting. They adopted a resolution that "expressed serious concern" about Iran's decision to resume "uranium conversion activities" (IAEA and Board of Governors 2005a). At the next regular meeting in September, the board determined Iran to be in noncompliance with its safeguards agreements deriving from the Treaty on the Non-proliferation of Nuclear Weapons (IAEA and Board of Governors 2005b). In January 2006, Iran again removed seals, this time from another nuclear installation — a uranium-enrichment facility in Natanz-and, in early February, the Board of Governors, as provided for in the IAEA's statute (IAEA 1956, Art. 3, B.4), referred the Iran case to the UN Security Council (IAEA and Board of Governors 2006) as a matter of "international peace and security."

When Iranian workers removed seals in August 2005, the controversy surrounding the country's nuclear program reached a new level of geopolitical intensity. The Guardian's headline shouted, "Iran Risks Showdown as Atomic Work Resumes" (Traynor and MacAskill 2005). USA Today claimed that by removing the seals, "Iran escalated a confrontation with the West." Global actors interpreted the fact that Iran broke IAEA seals as an act of "brinkmanship" (Beeston 2005), signaling that the country no longer wanted to cooperate with the ostensibly generous international efforts to limit its nuclear program ("Offer by Europe Would Give Iran Nuclear Future” [Weisman 2005]). Iran, on the other hand, argued in its August 2005 seal-breaking-announcement letter to the IAEA that it was reacting to the "broken promises" (IAEA 2005, 2) of its negotiating partners whose 
proposal had fallen short of Iranian expectations. Iran's letter sought to present an alternative explanation for the seal-breaking, one that hinged on what the state understood as its right to peaceful nuclear technologies.

Nevertheless, in the following months, these broken seals became an increasingly unequivocal sign of Iran's bad intentions for the international community. How did Western concerns about the intentions of Iranian nuclear efforts, what Gabrielle Hecht (2007, 103) calls Iran's "nuclearity-as-world-crisis," crystallize so naturally in the broken seals themselves at this moment, obstructing all other possible interpretations? What makes broken seals such "natural" metaphors for a broken promise? And why had there been no comparable public outcry twelve months earlier, when Iran removed seals from R \& D-stage centrifuges for uranium enrichment in July 2004 (IAEA and Board of Governors 2004, 28)? This article follows interpretive interactions between nuclear inspectors, seals technicians, diplomats, and journalists from which emerge the multiple meanings attributed to seals across their material states of intactness and brokenness. I argue that it is these actors' ontological understandings about the functions of signs, the agency of entities, and the effect of materiality that simultaneously presuppose and entail the meanings that can be made of the seal. In this context, seals are neither only signs nor things. Instead, they make up the semiotic infrastructure of nuclear governance that materializes international law and geopolitical relations between states through the IAEA's supposedly neutral techno-epistemic devices and practices of interpretation.

Building on recent work in science studies, semiotics, and anthropology, this article takes the role of seals in the controversy surrounding Iran's nuclear program as a vantage point for reflecting on the relationship between things, signs, and meanings in the putative democracy of the global political order. Beginning with an ethnographic view of the life of the tamper-indicating seal at the IAEA and closing with an archival reconstruction of the events that led to Iran's referral to the UN Security Council in early 2006, I chart the career of the seal as it is mobilized to produce geopolitically consequential knowledge about nuclear programs and state intentions.

\section{SEALS AS SEMIOTIC INFRASTRUCTURE}

Tamper-evident seals originated roughly 7,000 years ago (around the same time as the earliest writing systems) and have been found all over the world (Collon 1997). They are primarily made of clay, wax, metal, plastic, and even paper, and are used to facilitate political and economic administration. In addition to 
indicating tampering, seals may also signal origin, authorship, authenticity, or provide authoritative information, thus facilitating the flow of goods, services, and information. ${ }^{2}$ Yet we should be careful not to presume that the seal's functions have remained stable across time and, rather, investigate how social actors understand them to function (Bedos-Rezak 2010). As lowly, commonly invisibilized yet ubiquitous material artifacts (Star and Lampland 2009) that support the functions of a complex society, seals are infrastructure. Like infrastructure, too, seals jut into consciousness most prominently when they break. Once broken, though, a particularity emerges that sets them apart from regular infrastructure: seals were designed to signify. To be sure, conventional infrastructures clearly have signifying tasks, for example by transmitting information about usage (Anand 2015) or by transporting symbolic dimensions as "metapragmatic objects, signs of themselves" (Larkin 2018, 189). Yet while technocrats generally seek to avoid infrastructure's breakdown - which may incidentally communicate information about adherence to a contract (von Schnitzler 2013) — the seal's breakability forms part of the script (Akrich 1992). Seals are designed as a binary sign: they are either intact or not.

At the IAEA, tamper-indicating seals - drawing on a long history as "devices to make honesty unnecessary" (Collon 1997, 9) — serve as semiotic infrastructure for the flow of trust and the accumulation of confidence across nations participating in the global assemblage (Ong and Collier 2005) of the nuclear nonproliferation regime. As part of this regime, the IAEA sends inspectors into the non-nuclear weapon states that are party to what is known as the Nuclear Nonproliferation Treaty (NPT) of 1970. These states have promised not to build nuclear weapons, and the IAEA "verifies" these legal promises. ${ }^{3}$ Verification ostensibly establishes the truth of a claim. The legal promise itself cannot be relied on to affect the state's intention and consequently its behavior, so the verification regime and its use of seals comprise the technocratic solution to the anthropological question of "mind opacity."

Because we cannot know for certain what others intend, seals function as passive artifacts that act as apparently undeniable, literally material witnesses of whether a state's public expression matches its privately held intention. At the same time, seals effect the pragmatic, real consequences of the promise by gently compelling compliance. An inspector described the seal to me as a "sleeping inspector," modifying the state's behavior through its material presence, much like the speed bump embodies a "sleeping policeman" (Latour 1999, 186). The speed bump achieves pedestrian safety because drivers slow down to avoid damage to their vehicles. The seal's materiality, however, is not as rigid as that of the speed bump. 
The seal can easily be cut, broken, or removed: it retains for the state the option of noncompliance. And indeed, the seal's material fragility enables its script: through the seal the state can communicate its compliance, or, as in the case of Iran, its refusal.

As such the seal seems to operate as a passive receptacle for signifying an actor's intention, a form of verbatim technology (Inoue 2018). But as Miyako Inoue (2018) reminds us, the effect of immediacy emerges from the social construal of the semiotic medium as neutral conduit. The seal's lack of agency is presupposed and entailed by the social actors' semiotic ontologies, that is, their "ensembles of assumptions [about] the world" (Kockelman 2013, 3), which are both an outcome of meaningful interaction and a condition for it. In contrast to the material semiotics of science and technology studies (STS) scholars (Akrich 1992; Akrich and Latour 1992; Latour 1992; Law and Mol 1995), which is careful not to privilege human agency or to distinguish between things and people in its description of how actors assemble into networks, Peircean material semiotics reintroduce actors' ontologies as key "missing masses" (Latour 1992) that invisibly shape how social individuals construe the world around them. With the seal, I analyze not only its institutional travels but also its interactive interpretation in the meetings of the Board of Governors. Legal anthropologists point out that the stated goals of an interaction prove important for analyzing it. Dispute interactions constitute a special case, because they are "speech events where calculating responsibility and meaning is the public, institutional goal of the interaction" (Richland 2006, 75). They are therefore most likely informed by specific sets of ideologies and conventions. In the case of the seal, its entry into a public forum in which the participants' stated goal of the interaction is to assign responsibility for the seal's condition requires a theory that can account for how social actors interpret signs.

How to understand the relationship between materiality and meaning has been the concern of both linguistic anthropologists and infrastructure scholars. In a recent piece, Brian Larkin $(2018,175)$ pushes back against new materialist approaches in an effort to examine how the "political aesthetics" of infrastructure express its "political rationalities," which people experience sensorially. Similarly, Susan Gal (2017) argues that the sensory experience of the material qualities of porcelain (its durability, its milky whiteness) have been structured by regimes of value that changed over time. Antina von Schnitzler (2013, 671), too, describes how changing regimes of value across time and space transform the meanings ("political terrain”) of the prepaid meter. Webb Keane (2003, 414), however, attributes the changing construal of an object's material qualities (indeed, of the 
change in which qualities are saliently construed) to any object's necessarily "bundled" material qualities. An object's qualities are not stably construed. The seal's material qualities - such as the oxidizability and markability of the metal or the fragility and the tieability of the sealing string-emerge through semiotic process in ontological context (see also Chumley 2017). Larkin (2018, 186), too, argues against assigning inherent ontological properties (such as invisibility) to infrastructure. He proposes that these properties "are made to happen as part of technical, political, and representational processes."

Yet one parameter that importantly limits the range of interpretations possible in any given interaction is the ontological attribution of agency to individual entities. Paul Kockelman $(2007,2013)$ theorizes agency as the semiotic processes by which an actor's flexibility to control their behavior and anticipate its effects is put in relation to the actor's accountability (in terms of rights and obligations) to others in a social-semiotic context. This means agency is "necessarily contextually contingent, interactionally emergent, and ontologically framed" (Kockelman 2013, 84). At the IAEA, seals are generally not thought to possess agency, because they cannot be held accountable for what happens to them. Bureaucrats, diplomats, journalists, and their audiences regard seals as passive devices that display what a human subject has done to and with them. Seals' lack of agency makes them credible. People — full of contingent agency — may lie, but seals always tell the truth.

Yet to signify unequivocally, the IAEA's seals and their administrators are tightly regimented by bureaucratic process and procedure. This process effectively removes agency from the seals, transferring accountability to the social individuals that handle them. Moreover, the process "transduces" (Silverstein 2003) what the seal means from the inspectorial realm of formal accountability to the public realm of political responsibility. The following section on the use of seals at the IAEA illustrates how bureaucrats regiment the seal material so that a maximally unambiguous interpretation of its status can be achieved. The subsequent section takes up a moment of seal-breaking and the effort of diplomats to attribute intention and assign responsibility to demonstrate that even a supposedly unequivocally broken seal is subject to the inherent contingencies of semiotic process in which "signs give rise to new signs, in an unending process of signification" (Keane 2003, 413).

\section{SEALS AT THE IAEA}

Among the substantial historical and political science scholarship on nuclear governance (Shaker 1980; Hecht 2012; Mallard 2014; Holloway and Nuti 2018), 
and the IAEA in particular (Bernstein 1974; Scheinman 1987; Brown 2015; Hamblin 2016; Holloway 2016; Roehrlich 2016), the technical aspects of nuclear science and its applications are readily acknowledged as significant for the way the regulatory assemblage of nuclear governance has taken shape. Yet with few exceptions (Forland 1997; Pouliot 2010; Roehrlich 2018), the verification mechanisms themselves, not to mention their material qualities, have not proven analytically central to this scholarship (which tends to focus on power, states, interests, etc.) Indeed, aside from gray literature among the technical and policy professionals who are expert practitioners in this world, the verification system itself remains largely unexamined.

During the time of my fieldwork at the IAEA, wide-ranging debates raged about the methodological changes to inspectors' evaluation of state compliance (Weichselbraun 2016). But seals, as uncontroversially technical artifacts, clearly remained outside that vortex of controversy, so it was easy for me as an intern in the training section of the safeguards department to speak to people about seals and to learn how they worked. In that way, seals (and the array of technical devices for carrying out nuclear inspections) resembled infrastructure in that they faded into the background, unnoticed, until_- perhaps — they failed.

Within the nuclear-verification system, seals assist the inspector in evaluating if a state is complying with its legal agreements. In the high-profile case of Iran breaking seals in 2005, the seal's signifying capacity initially appeared straightforwardly binary: the seal was either intact, signifying compliance, or it was broken, signifying noncompliance. Contrary to this common-sense view, I contend that the seal's signaling capacity should be seen as the outcome - not the starting pointof the seal's semiotic properties; its common-sense emblemeticity is the puzzle to be interrogated (Kockelman 2013, 78-79). The labor of the seal's administration as a piece of evidence is distributed along a "chain of custody" akin to the forensic DNA testing in criminal trials described by Michael Lynch et al. (2008). In what follows, I examine the elements of the chain to explore the seal's varied semiotic regimentation. To become stable signs of geopolitical sincerity, seals undergo semiotic transformations, beginning as meaningless pieces of metal and returning to headquarters as witnesses of radiation or bad weather, or as victims of accidents; their component parts index professional vice and virtue, and their residues accrete into the evidence of inspection work for the inspectors and technicians at the IAEA. 


\section{ADMINISTERING THE SEAL}

Inspectors from the IAEA use about 22,000 metal seals in the field per year, making them the most widely used seals. The total cost of a metal seal is up to US\$40, of which only US\$3 are in the material itself. The rest of the cost goes into the seal's administration. Metal "double cup" seals are composed of two parts, a copper-colored cap or casing and a brass-colored disk, the seal body as seen in figure 2 .

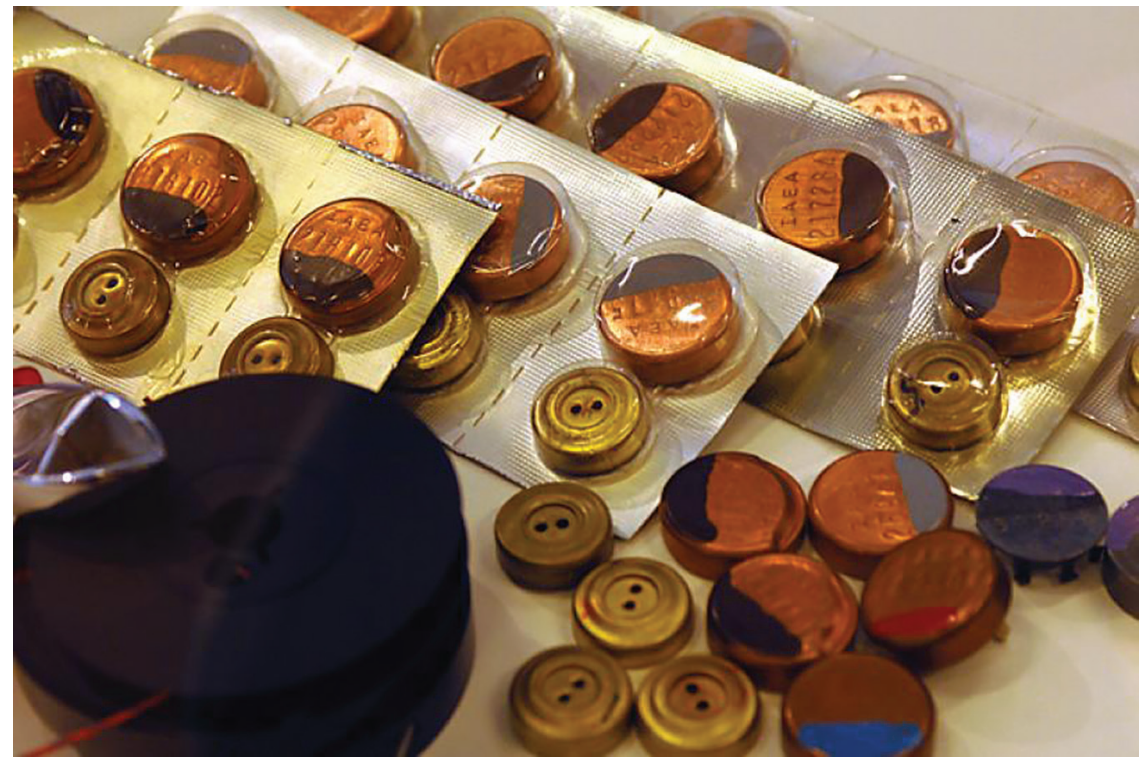

Figure 2. Loose and packaged seals used in training. Photo by Dean Calma/IAEA.

Usually, a given seal design will only be used in the field for a limited number of years, because seals professionals presume that the longer the seal remains in circulation, the more likely it is to be "defeated" (that is, opened without evidence of tampering). Metal seals, however, have been used by the IAEA for more than forty years. Seals technicians at the IAEA consider them very "robust," because they have not yet been defeated. Seals experts contest this assumption, however, noting that "[by] definition, defeated seals are never detected" (Johnston 2001, 106). But it is not only the seal's material design that contributes to its robustness. It must also form part of a controlled system of protocols that account for the trajectory of the seal. As seal professionals note,

The effectiveness of seals is strongly dependent on the proper protocols for using them. These protocols are the official and unofficial procedures used 
for seal procurement, storage, record keeping, installation, inspection, removal, disposal, reporting, interpreting findings, and training. With a good protocol, a modest seal can provide excellent security. On the other hand, a sophisticated seal used poorly may be worse than useless if naively trusted. (ANL, Nuclear Engineering Division 2013)

Trust in a seal becomes delicately accumulated as the seal travels through the multiple protocolled stages of its life within the safeguards system. Seals are assiduously cared for in order to become the reliable semiotic forms that signify a state's compliance. The IAEA's protocols attempt to ensure that the seals are effective, robust, and therefore trustworthy from the seal's "birth" to its "postmortem" analysis.

\section{Birth}

The life of the IAEA metal double cup seal begins with its manufacture in the United States, where the IAEA letters and a six-digit serial number are stamped onto the outer casing. At the IAEA's laboratory south of Vienna, Austria, technicians punch two holes into the seal body and create its signature by dropping hot liquid soldering metal inside the casing and scratching it with a metal tool as it dries. These scratches are thought to be unique, like a signature, because they are made by hand. The belief in the signature's uniqueness hinges on this "ostensibly inimitable biomechanical act, signing" (Hull 2012, 131). In contrast, however, to the written signatures of Pakistani bureaucrats that Matthew S. Hull $(2012,131)$ describes, the scratched signatures produced inside the metal seal are not put in "semiotic relation" with a specific individual. They are not seen as a "natural" sign (Grice 1957, 378). In fact, once the seal cap is applied, the seal's signature becomes concealed. This signature, in combination with the seal's six-digit serial number, establishes the seal's unique identity. The seal, at once unique but also sharing a family name with thousands of other seals, therefore serves as an indexical sign of the IAEA and its authority in the state's facility. That is to say, the seal is a sign that is interpreted (by inspectors, diplomats, and facility operators) as representing the IAEA as its object via an understood spatiotemporal contiguity between sign and object. ${ }^{5}$

\section{Initialization}

Once lab workers have baptized the seals with hot metal, they pack them in boxes of ten into secure suitcases that can each hold fifty boxes, and send them to 
the seals laboratory at the IAEA headquarters in Vienna. There, at the base of the towers, seals technicians sort the metal caps according to their serial numbers and place them in numerical order on a large tray with a hundred cutout circles for fifty seals. They receive one suitcase - five hundred seals — per week. Using markers, technicians copy the last two digits of each seal's number onto the seal body part, creating pairs that belong together. They photograph each side of the seal cup and body with a mounted camera. The technicians save the images to a database with metadata such as the serial number, date, and batch number. Once the seals have been thus "initialized," the technicians batch-package them in cardboard and in sealed plastic individual packages (see figure 3).

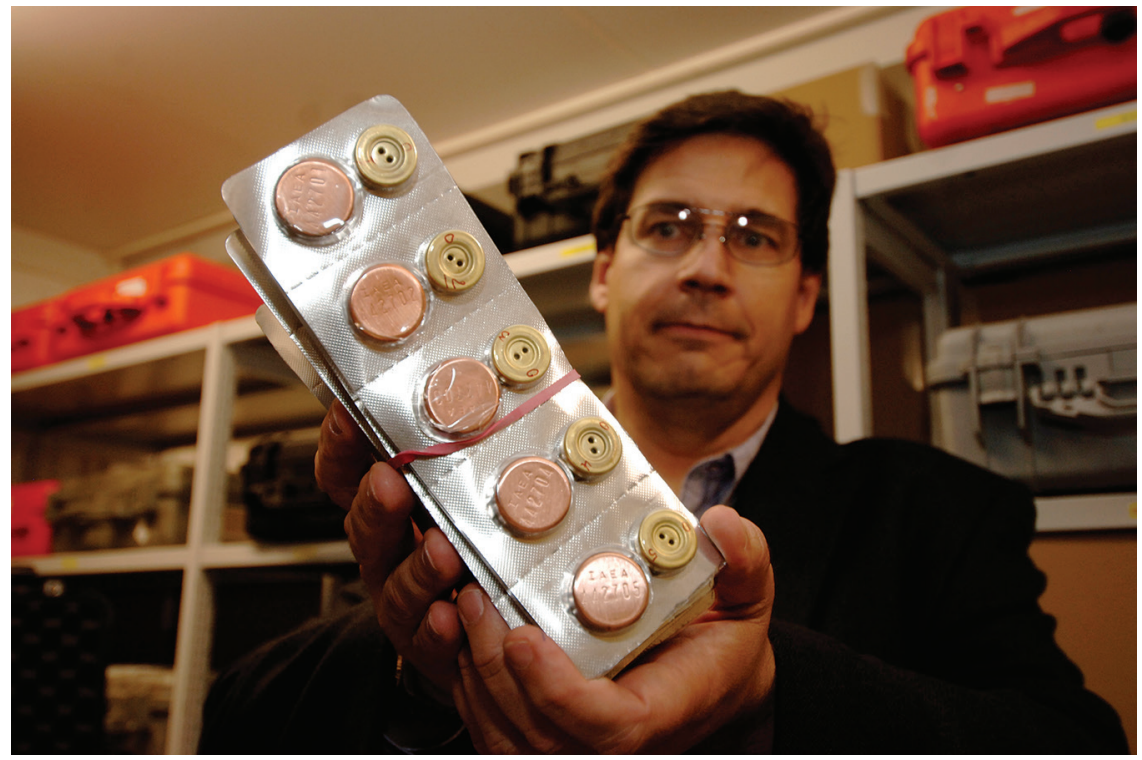

Figure 3. Sealed seals. Photo by Dean Calma/IAEA.

It usually takes three days to enter a suitcase worth of seals into the database, though one technician told me he could do it in one day. The labor-intensive process of endowing seals with their unique identity and registering their qualities within a database permits them to then begin to circulate as entities with potential meaning. But they do not become meaningful until the moment they are attached.

\section{Learning to Apply a Seal}

"Make sure you tie the knot neatly; the way we tell you to. The knot is part of the seal that is verified when it comes back from the field. A badly tied knot can reflect badly on you. There's an error code for that!" The trainer's warning 
rings across the table where I am sitting. On the table, rolls of string and loops of wire, metal bits and bobs, and various tools are scattered about in piles. It was an afternoon in the training-section workshop space and I, the intern, alongside four newly hired inspectors-in-training, was learning and practicing how to apply the IAEA's tamper-indicating seals. This made for a nice change from sitting behind desks in the training classroom where I had been observing how new inspectors are trained to do their job, with text-laden slides flashing on monitors while lecturers droned on about technical topics.

Following the trainer's demonstration, we grabbed some parts and began to practice. I took the sealing thread and strung it through the two holes of the metal button. I made a triple square knot, laying one string over another in a specific pattern. Then I cut off the extra thread with a pair of scissors. To close the seal, I snapped the copper-colored seal casing over the seal's body, concealing the knot, and spun the casing to make sure it moved freely. Next, I practiced applying a seal with sealing wire instead of thread.

The purpose of this exercise was to gain enough practice to be able to apply seals in the more challenging conditions in the field. Applying a seal at this desk proved easy enough but - the trainers warned us - the encumbrances of nuclear facilities included gloves, heat, cold, sweat, fatigue, thirst, and needing to use the bathroom, making this task exponentially more difficult.

\section{Sloppy Knots}

Just as the seal is disciplined into becoming a meaningful technical device through rigorous administrative procedures, so the practice of sealing is also meant to discipline the inspectors. Thus the seal can become a sign not just of state compliance or noncompliance but also of the quality of the inspector. The seal has multiple material qualities "bundl[ed]" (Keane 2003, 414) into one object. Depending on the context, the "relative value, utility, and relevance" (Keane 2003, 414) of these qualities will shift. In the processes of the internal administration of the seal, the qualities of the seal's knot (its neatness, its sloppiness) take center stage when it comes to evaluating the inspector's professional skill.

The trainer who led my seal-practice session explained to me in his office - a poster with photographs of correct and incorrect sealing practices up on the wall behind him - that inspectors needed to heed the importance of making proper knots. A good inspector tied tidy, proper knots, whereas a bad inspector, who did not take their work seriously, tied sloppy knots of an insufficient number and incomplete form. The seal knot constituted an integral component of the seal's 
tamper-indicating function, and needed to be diligently tied. Even if trainers acknowledged that applying seals could be tricky in the field, they still frowned on poorly constructed knots. In the way they spoke about inspectors who had tied bad knots, the trainers indicated that they thought these new inspectors lacked the wherewithal to carry out the inspection task. They saw the task of tying a proper seal knot as an indication of aptitude and read sloppy knots as indexical icons of inspector incompetence.

\section{In the Field}

Wearing the faded yellow underwear issued by the nuclear power plant beneath a rough cotton_-bright yellow_-jumpsuit, safety boots like cement blocks on her feet, borrowed socks slipping down past her heels, Elizabeth struggles with her gloved hand to pull sealing wire through the two holes of the metal button that is one half of a seal, all while trying to ignore her sweaty scalp itching underneath her hard hat. ${ }^{6}$ The little device gingerly immobilizes the vault door containing nuclear material and will_ by virtue of its material fragility — indicate if anyone has tried to get into the vault. Elizabeth pushes the seal body snugly around the door handle and ties four square knots, nice and tidy. The recommended number is three, she likes four, some people go overboard and tie six knots, but Elizabeth knows that six knots can make it hard to close the seal. She snips the excess sealing wire and pushes the cap onto the body, closing the seal with a satisfying snap. Spinning the cap around the body, Elizabeth reassures herself that the seal is properly put together. Picking up her clipboard, she notes the seal's serial number and location in the power plant on the designated form. She puts the seals she replaced today in her clear plastic bag, glad that her work is completed and eager for a glass of water.

Reflecting on the role of seals, Elizabeth tells me: "Nobody cares about seals before they're attached; they're just pieces of metal. But once they're recorded, once they're attached, they become more than pieces of metal and string."

An individual metal seal may stay in the field up to three years depending on environmental conditions. In the field, the intact seal becomes a sign of the state's compliance with international law. It signals a promise kept, the alignment of words and deeds. Bruno Latour $(2000,19)$ claims that "meaning does not antecede technological devices." Instead, meaning emerges from and with the device and its inclusion in a "chain of associations." The seal, then, presents itself as particular kind of technological device because it was designed and is administered to produce particular and limited kinds of meaning. Like traffic lights, seals are 
technologies of nonverbal communication that are culturally expected to be selfevident, and - predominantly - binary in signaling capacity. Once a seal is attached, its meaning lies in being either intact or broken; these two states entail the significations of compliance or noncompliance. For the IAEA's technicianbureaucrats, however, the seal communicates more than this.

\section{Postmortem Analysis}

Back at headquarters in Vienna, Elizabeth turns in the seals she collected in the field to be decontaminated before the seals technicians cut them open (with an "expensive can opener") and examine them for tampering. The seals technicians again take a picture of the unique signature of metal scratches inside the seal cap, and check it against the picture in the database. They note the seal's condition and send these findings to Elizabeth who is relieved that all the seals are "verified." She can now complete her report and send a letter notifying the state that the inspection was satisfactory. She tells me, "99.9 percent of the time the results of the inspection are satisfactory."

Sometimes, however, the seals technicians note problems with the seal according to a list of codes of increasing severity. Seals may be returned with a code indicating an issue of low severity but nevertheless be verified. For example, the knot may have been tied incorrectly, but the technician's forensic analysis determines that the seal was not compromised in its sealing function. The situation worsens when the seal is returned "unverified." This means that the seal can no longer be trusted to have provided effective tamper-indication. For example, if the seals technician finds a slip knot inside the seal, the seal's tamper-evidence function was compromised.

The codes identify whether or not the seal can be verified, and characterize how the seal's condition diverged from the ideal. In the case of unverifiable seals, the inspector then must determine the seriousness of the seal's unverifiability, which depends on what kind of thing the seal had sealed. The inspector will check her inspection paperwork for the location from which the seal was removed. If the seal had been placed to secure a box of inspection equipment overnight, the inspector might decide that it suffices to reinitialize the databases of the equipment before returning to that facility the next time. If the seal had been placed on nuclear material, however, the amount of sealed nuclear material becomes significant.

Below a certain threshold of nuclear material, inspectors do not worry about a broken seal. ${ }^{7}$ Above this threshold, the unverifiable seal indicates a potentially dangerous loss in the "continuity of knowledge" about that facility. Still, if the seal 
had secured a large amount of nuclear material, it was likely not alone-there would be complementary surveillance video and containment devices to verify. The inspector could check the footage of the surveillance camera to figure out why the seal had come back unverified. Perhaps facility crews had accidentally damaged the seal with another piece of equipment. The inspector might get in touch with the facility operators to find out more information about potential damage to the seal so as to understand what happened.

When seals come back unverified, one inspector told me, "everyone's trying to come up with a credible story." There are multiple plausible reasons why a seal may be unverifiable that do not indicate the nefarious intentions of individual actors. But in the case of an unverified seal on a large amount of nuclear material, the inspector has to restore the agency's so-called continuity of knowledge about that material as quickly as possible, by arranging an urgent return visit to the site and recounting all unsealed material. The chain of custody can be unfolded (like a chain of paper dolls [Lynch et al. 2008, 129]) to reveal individual steps and heterogeneous practices in the procedures to administer tamper-evident seals.

The chain of custody to maintain the IAEA's semiotic infrastructure of nuclear trust among nations serves as a funnel through time. Custodial practices progressively groom the seal's signifying capacity, from a material void of meaning ("just a piece of metal") to an "unverified" seal containing a multitude of potential "stories" to produce an unequivocally binary sign: open/closed, on/off, broken/ intact. At the moment when Iran announced that it planned to remove seals from its fuel-fabrication equipment, the binary signaling capacity of the seal was unambiguous. The broken seals stated clearly that the state had broken the seal. But the seal was mute on the state's intention. And from this point forward the funnel widened again to accommodate proliferating interpretations about what the broken seal meant. At the same time, the naturalized emblematic understanding of a broken seal as a broken promise acted centrifugally to consolidate meanings again.

\section{OF WHAT ARE BROKEN SEALS A SIGN?}

In moving from the bureaucratic accounting of seals to the diplomatic negotiation of the meaning of broken seals, we also move from a realm of formal accountability to moral responsibility. What is a problem for maintaining the continuity of knowledge about a state's nuclear material for the safeguards inspector becomes a problem of ascertaining the degree and quality of commitment of a state to the moral nuclear order. The diplomats representing their countries on the IAEA's Board of Governors are responsible for drawing up the board's response 
(usually, a "resolution") to the report of the broken seals. In this forum, the broken seal most loudly emerges as a sign not of a broken promise but of an uncertain intention. While Iran proffered an interpretation of its action, the other diplomats sought to uncover what lies behind that interpretation. Furthermore, not all broken seals are alike: seals broken (while voluntarily applied) in the context of diplomatic negotiations turn out to be far more consequential than seals broken without such an additional layer of interactional constraint.

\section{Iran Breaks Seals}

For the purposes of this article, the Iranian nuclear story began in the middle of 2002 when the United States briefed the IAEA on a previously unreported nuclear facility for uranium enrichment in Iran (Lewis 2006, 2007). This revelation proved an unpleasant surprise for the IAEA. The agency asked Iran for clarification and access to the site, which Iran eventually granted in early 2003. Inspection visits by the IAEA eventually indicated that Iran — despite claiming to have developed their facilities indigenously_ _ procured components of its centrifuge enrichment from Pakistan. ${ }^{8}$

During the subsequent eighteen months, the IAEA attempted to understand the extent of Iran's previously unmentioned nuclear activities, while Iran oscillated between periods of cooperation and recalcitrance. In November 2003, then director general of the IAEA, Mohamed ElBaradei, presented the first comprehensive report on the scope of Iranian nuclear activities. The report stopped short of declaring Iran noncompliant. ElBaradei $(2011,120)$ wrote in his memoir, "None of these activities pointed explicitly toward a nuclear weapons program, but together they constituted a fairly comprehensive nuclear fuel cycle program, most of it conducted in secret." Western states on the IAEA's Board of Governors widely interpreted Iran's clandestine acquisition of "sensitive" nuclear technologies as an indicator that the country was up to no good. Diplomats began calling for "confidence-building measures" to "provide assurances" that Iran's nuclear program had solely "peaceful purposes” (ElBaradei 2011).

In the spring of 2004, American anxiety about a potential Iranian nuclear weapons program began growing. ElBaradei remembered CIA Director George Tenet, in particular, as convinced that Iranians intended to build nuclear weapons. ElBaradei noted that U.S. officials would repeat to the news media that they "knew" Iran was trying to build a bomb, but had no evidence to demonstrate this. He mused that Americans seemed to be "hoping the Iranians would trip up somewhere during the inspection process" (ElBaradei 2011, 133). At the same time, 
Iran's conservatives gained control of the Majlis (parliament) and the country's nuclear program had become a matter of national pride. When a board resolution in June 2004 deplored the lack of progress on clarifying outstanding questions on Iran's nuclear program, the Iranians grew annoyed and removed seals they had voluntarily placed on R \& D centrifuges. They resumed manufacturing and testing of the equipment. This was the first time that Iran broke seals.

In November 2004, Germany, France, the United Kingdom, and Iran announced a preliminary agreement that would provide the basis for further discussions: Iran agreed to suspend uranium-conversion and centrifuge-enrichment activities (and voluntarily place seals to indicate this suspension) to negotiate a deal that would permit “objective guarantees that Iran's nuclear program was exclusively for peaceful purposes" (ElBaradei 2011, 141). This would be called the Paris Agreement. In the months following, expectations were high for a positive outcome to the negotiations. In March 2005 the Iranian issue had - for the first time in two years — not been on the meeting agenda of the IAEA's Board of Governors. But in May 2005 the Iranians threatened to leave the negotiations because of slow progress, and the Europeans agreed to provide an initial offer by August. In late June of that year, the Iranian conservative candidate Mahmoud Ahmadinejad won the presidential election. In July, details trickled in from the soon-to-be delivered European proposal, which fell far short of Iranian expectations.

On August 1, 2005, Iran submitted a letter to the IAEA in which it expressed its frustration with the negotiations and announced that it would resume uranium conversion. The letter instructed the IAEA to carry out the necessary steps to maintain safeguards monitoring of the facility. On August 3, Ahmadinejad assumed office and workers began feeding uranium oxide into the unsealed portion of the uranium-conversion facility. On August 10, after Iran received a formal offer from the Europeans, $B B C$ News reported that "Iran has broken all the remaining UN seals at its nuclear plant at Isfahan.” This was the second time Iran had removed seals. During the subsequent emergency session of the board, the IAEA governors issued a resolution that urged Iran to re-suspend its conversion activities. At the regular meeting in September, the board declared Iran to be in noncompliance with its IAEA safeguards agreements for the first time. ElBaradei (2011, 145) noted that some critics responded with "cynicism" because the claim of noncompliance referred to his report from two years prior. If that formed the basis for the noncompliance finding then Iran had been noncompliant all along, without being identified as such. Subsequent attempts at negotiation went nowhere, because "forces against it were too strong" (ElBaradei 2011, 147). 
On January 10, 2006, Iran resumed its enrichment activities, breaking seals on the centrifuges and moving closer to the "nuclear threshold" identified by Western states. This was the third time that Iran removed seals. In response, a special session of the IAEA's Board of Governors on February 4, 2006, referred Iran's case to the United Nations Security Council (IAEA 1956, Article XII, C).

\section{Conditions for Semiotic Transduction}

The IAEA's semiotic infrastructure accommodates multiple registers for the interpretation of seals. In a period of nineteen months, the Iranians removed IAEA seals from two of their facilities three times and replaced them once. For the three times that Iran broke IAEA seals between 2004 and 2006, only the first time made it difficult for the IAEA to maintain effective safeguards. When Iran removed seals the first time in June 2004, the IAEA reported that "in the absence of such seals, the Agency's monitoring . . . cannot be considered effective" (IAEA and Board of Governors 2004, 28). In contrast, during the following year's episode that precipitated the emergency Board of Governors meeting and the eventual finding of noncompliance, agency surveillance continued unhindered. An IAEA spokeswoman stated that despite the removal of seals, "we went from a mode of monitoring a frozen facility to a mode of monitoring an active facility" (Avni 2005a). As described above, seals help maintain continuity of knowledge about a state's nuclear material. If the IAEA was effectively able to maintain this knowledge without seals in August 2005, why did the seal-breaking have such negative repercussions for Iran in this case?

Beyond not having negative repercussions for Iran, the 2004 seal-breaking episode is not even remembered by participants. In a white paper describing the events, Pierre Goldschmidt, the head of safeguards during this period, provides a timeline of events from 2002 to 2006. In it, only the second two instances of seal breaking in 2005 and 2006 are mentioned as such. ${ }^{9}$ The white paper describes the initial seal removal in 2004 as "Iran informs ElBaradei of its decision to restart the fabrication and testing of centrifuges" (Gerami and Goldschmidt 2012, 19). Furthermore, when I asked an Iranian diplomat who had participated in these negotiations about the seal-breaking episodes of 2004-2006, he corrected me, "you mean 2005 and 2006." What explains this?

In 2004 Iran was only accountable to the IAEA, the techno-bureaucratic actor. Within that context, seals were merely part of the register of formal accountability. Breaking seals was thus nothing more than annoying some inspectors. And indeed, the 2004 seal-breaking episode even had arguably constructive 
effects for Iran in that, shortly thereafter, the above-mentioned Paris Agreement was drawn up, mutually orienting Iran, Germany, France, and the United Kingdom in a moral-diplomatic framework. When I asked the same Iranian diplomat why his state was then referred to the Security Council if its violations had been known for some time already, he responded, "because of the Paris Agreement." Goldschmidt, too, interpreted Iran's action to remove seals again and "resume uranium conversion activities [as] nullifying the Paris Agreement" (Gerami and Goldschmidt 2012, 12). In other words, the formal diplomatic process - and the actors' ontological assumptions about the telos of such a process - added interactional, social-semiotic constraints to the unfolding situation. The state's actions were then interpreted in light of the agreement's goal to "build confidence." In other words, the Paris Agreement transduced the seal's signals from a register of formal adherence to a set of rules to a register of moral responsibility within the nuclear order.

\section{What about Intention?}

A Western diplomat noted in August 2005 that while the IAEA suspected that Iran was not forthright about its nuclear activities, it could do little about that because the NPT "does not deal with intentions" (Avni 2005b). Breaking seals publicly, as Iran had done, clearly constitutes a form of "communicative, purposive social action," which Jack Sidnell $(2017,87)$ notes "is semiotic and involves one person getting another to recognize her intention.” Recognizing and identifying the intention that motivated the seal-breaking act became the work of the IAEA's Board of Governors emergency meeting in August and September 2005.

The press as well as diplomats offered interpretations for the meaning of the broken seals. The New York Times reported that the "removal of the seals was part of Iran's tough stance on its nuclear program under the conservative new president, Mahmoud Ahmadinejad, who took office this week" (Fathi and Fuller 2005). Meanwhile, a U.S. diplomat used the seal as a prop:

The American envoy to the talks . . . Mr. Schulte appeared at a news conference brandishing a copper seal used by the United Nations agency to monitor equipment and praised the action of the governing board. The resolution on Thursday "shows that the international community is united in its determination that Iran move off the dangerous course that it is on," he said, holding up the seal. (Fuller and Fathi 2005; emphasis added) 
Both the New York Times and Gregory Schulte sought to mobilize the apparently obvious emblematic (Kockelman 2013, 8-9) meaning of a broken seal as iconic of the broken and necessarily nefarious intentions of the seal-breaking state. Yet both of these comments ("tough stance," "dangerous course") are rather more evocative than explicit, indicating that the broken seal's meaning had not yet been determined.

Iran removed seals and the governors attempted to understand the meaning of this action. Their response would assign responsibility and lay out steps for future action to restore the destabilized order. Within the context of diplomacy and its repertoire of available actions and strategies, breaking seals might indicate a variety of intentions. Does the actor mean to signal their impatience? Is this to be taken as a threat or a bluff? The diplomatic effort was directed toward locating the state's intentions on a spectrum of motivation from indecision to determination, while simultaneously crafting strategies for responding to their presumed motivation. In the end, the governors argued that this episode has reduced confidence in Iran's intentions.

The judgment, and referral to the Security Council, ultimately concerned the diplomats' collective uncertainty about the intentions of the Iranian nuclear program. As John W. Du Bois $(1993,69)$ notes, "the dynamic of invocation and suppression of intention carries social meaning in itself." After Iran broke seals in January 2006, the Board of Governors referred to Iran's "intentions" for the first time in a resolution in the following, generically atypical, paragraph:

[The Board of Governors] calls on Iran to understand that there is a lack of confidence in Iran's intentions in seeking to develop a fissile material production capability against the background of Iran's record on safeguards as recorded in previous Resolutions, and outstanding issues; and to reconsider its position in relation to confidence-building measures, which are voluntary, and non legally binding, and to adopt a constructive approach in relation to negotiations that can result in increased confidence. (IAEA and Board of Governors 2006, 3; emphasis added)

While the NPT does not deal (explicitly) with the intentions of states to remain inside the treaty or not, relations of trust and promise between states (coded as confidence in this paragraph) are mediated via seals and other devices making up the semiotic infrastructure of international treaty verification. While technicians work to hone the clarity of the seal's binary signal, what it ultimately signals must 
be negotiated in the board room. And, in an unexpected twist, the voluntarily applied seal possesses an even greater signifying force than the seal obligatorily applied.

\section{CONCLUSION}

From the IAEA's perspective, the Iranian nuclear story came to a closure of sorts with the agreement of the Joint Comprehensive Plan of Action in July 2015. Then-President Barack Obama (2015) declared that the agreement was "not built on trust, but on verification.” Herewith he cited - and revised - the dictum "trust, but verify" used by Ronald Reagan in the context of nuclear-disarmament negotiations with the Soviet Union for a newly distrustful domestic context. The fact that IAEA seals are still in place in Iran at the time of this writing remains a powerful symbol of the country's compliance with the agreement in spite of U.S. withdrawal from it. The Iranians are clearly aware of the common-sense signifying power of seals, broken and intact, and have mobilized these meanings in salient moments.

Conceptualizing seals as semiotic infrastructure, whose interpretation is not arbitrary in that it relies on powerful cultural tropes construable via sign users' semiotic ontologies, permits us to discover and analyze what counts as a sign. Approaches that favor aesthetics (understood as visual-sensory effect) and form (the analysis of features and qualities) are limited in that they are missing a metalanguage for discussing the socio-semiotic conventions by which seals become legible as signs.

As semiotic infrastructure, seals and other verification technologies do not merely produce information about states but also serve to techno-semiotically mediate relationships of trust and promise between states (this is in contrast to political scientists who imagine trust as "human factors" extraneous to technical elements [Bowen et al. 2018]). So what is often understood as a merely technical mechanism of formal accountability in fact becomes transduced into a register of moral responsibility when diplomats come to find states in noncompliance, and thereby in violation of their legal promises to the international community.

What distinguishes semiotic infrastructure from conventional infrastructure is that it continues to work even when it literally breaks down. In its function as a conduit for the flow of trust, the maintenance of international law, and the elaboration of relations between states, semiotic infrastructure only ceases to function once it is abandoned entirely. ${ }^{10}$ Breaking seals does not break the infrastructural system itself because semiotic infrastructure is designed to signify at all times. 
While the trust that the intact seals were meant to communicate can no longer be signaled, the normative expectations of the verification regime signaled via semiotic infrastructure itself remained, and continue to remain, intact.

By joining science studies with semiotics and the anthropology of infrastructure we can more readily understand the ways in which meaning and materiality are dialectically emergent in interaction. Through the example of tamperindicating seals as semiotic infrastructure we learn how technical knowledge is variously mobilized to construct and enforce a moral nuclear order against a background of always uncertain intention.

\begin{abstract}
In the world of global politics, talk is cheap. States sign negotiated agreements, but a treaty without an enforcement mechanism is considered weak, because states are not expected to adhere to commitments whose materiality is merely that of ink and paper. To verify the terms of state commitments to the Treaty on the Non-proliferation of Nuclear Weapons, which entered into force in 1970, International Atomic Energy Agency (IAEA) nuclear safeguards inspectors place tamper-evident seals in nuclear facilities. While seals appear to work simply as a binary signal, their meanings are multivalent. This article draws on fieldwork at the IAEA, and on broken seals in Iran between 2004 and 2006 that escalated into an international crisis, to examine the relationship between the material properties of the seal and its signifying potentialities. Bringing the perspective of semiotic ontology to the question of materiality, this essay argues that seals constitute a semiotic infrastructure of nuclear governance that materializes international law. [seals; materiality; meaning; knowledge; intention; agency]
\end{abstract}

\title{
NOTES
}

Acknowledgments For their critical engagement with this essay at various stages of becoming I am indebted to workshop participants at UCLA and the University of Chicago, as well as to Sarah Adcock (for pointers to the archaeological literature on seals), Hannah Chazin, Erin Debenport, Lynn Eden, Colin Halverson, Gabrielle Hecht, Cameron Hu, Vincent Ialenti, Anna Jabloner, and Jonathan Rosa. I thank four anonymous reviewers and the editors of $\mathrm{Cul}$ tural Anthropology, in particular Chris Nelson, for their generous readings and helpful comments. Research for this piece was funded by the Wenner-Gren Foundation, the Social Science Research Council, and the National Science Foundation. My sincere gratitude also goes to the kind souls at the IAEA (and beyond) who abided my curiosity with generosity and good humor.

1. The details of Iran's obligations to report nuclear facilities to the IAEA are contested, with the IAEA arguing that Iran should have done so earlier, and Iran maintaining that it had not broken any formal rules of reporting and was not planning on keeping the facilities secret.

2. The literature on seals is vast. For a concise overview, see Bonnie Magness-Gardiner (1997); for a classic volume on ancient Near Eastern seals, see McGuire Gibson and Robert D. Biggs (1977); and for an update, see K. Duistermaat, I. Regulski, and P. Ver- 
kinderen (2012). For a discussion of seals as precursors to the modern brand, see David Wengrow (2008).

3. Any verification regime appears to be buttressed by what Webb Keane $(2007,202)$ describes as the "sincerity as a moral norm" characteristic of Christian modernity, which makes a moral virtue out of aligning words and thoughts.

4. This topic has been the subject of lively anthropological discussion, particularly involving Melanesianists who note regional cultural preferences of "mind opacity." See the special issue of Anthropological Quarterly with an introduction by Joel Robbins and Alan Rumsey (2008). In an earlier edited volume, Jane H. Hill and Judith T. Irvine (1993) treat cultural variation in intention and speech.

5. Peirce's theory of the sign puts three elements in relation to each other: "a sign stands for an object on the one hand, and an interpretant on the other, in such a way as to make the interpretant stand in relation to the object in a way that corresponds with how the sign stands in relation to the object" (Kockelman 2006, 5).

6. My understanding of inspection work in nuclear facilities comes from a week-long mock inspection exercise I observed. "Elizabeth" should be understood as a composite of individual inspectors from whom I learned about their work.

7. This threshold is commonly cited as 0.1 SQ ("significant quantity") of uranium or plutonium. One SQ is the agreed amount of uranium or plutonium necessary to build a nuclear weapon. This agreement is not uncontroversial (Goddard, Solodov, and Fedchenko 2016).

8. In 2004 it became clear that a Pakistani national, A. Q. Khan, had been running an illegal nuclear procurement ring for states unable to buy nuclear technologies on the heavily regulated nuclear market.

9. "Iran required the removal of IAEA seals to the Isfahan uranium conversion facilities" and "Iran begins to remove IAEA seals at several enrichment-related sites," respectively (Gerami and Goldschmidt 2012, 19-20).

10. As did happen when the Democratic People's Republic of Korea ejected IAEA inspectors and left the NPT in an action widely understood as a breakdown of relations between states.

\section{REFERENCES}

Akrich, Madeleine

1992 “The De-Scription of Technical Objects." In Shaping Technology/Building Society: Studies in Sociotechnical Change, edited by Wiebe E. Bijker and John Law, 205-24. Cambridge, Mass.: MIT Press.

Akrich, Madeleine, and Bruno Latour

1992 "A Summary of a Convenient Vocabulary for the Semiotics of Human and Nonhuman Assemblies." In Shaping Technology/Building Society: Studies in Sociotechnical Change,

Anand, Nikhil edited by Wiebe E. Bijker and John Law, 259-64. Cambridge, Mass.: MIT Press.

2015 "Leaky States: Water Audits, Ignorance, and the Politics of Infrastructure." Public Culture 27, no. 2: 305-30. https://doi.org/10.1215/08992363-2841880.

ANL (Argonne National Laboratory), Nuclear Engineering Division

2013 "Vulnerability Assessment Team (VAT): About Seals." https://web.archive.org/ web/20150112133314/http://www.ne.anl.gov/capabilities/vat/seals/index.html.

Avni, Benni

2005a "Iranians Break IAEA Seals at Isfahan.” New York Sun, August 11.

2005b "New Reports Confirm Iran's Regime Is Hiding Nuclear Work from U.N." New York Sun, August 10.

Bedos-Rezak, Brigitte Miriam

2010 When Ego Was Imago: Signs of Identity in the Middle Ages. Leiden, Netherlands: Brill. Beeston, Richard

2005 “UN Nuclear Watchdog Backs Allies over Iran.” Times (UK), August 12. 
Bernstein, Barton J.

1974 "The Quest for Security: American Foreign Policy and International Control of Atomic Energy, 1942-1946.” Journal of American History 60, no. 4: 1003-44. https://doi.org/10.2307/1901011.

Bowen, Wyn Q., Hassan Elbahtimy, Christopher Hobbs, and Matthew Moran

2018 Trust in Nuclear Disarmament Verification. Cham, Switzerland: Palgrave Macmillan. Brown, Robert L.

2015 Nuclear Authority: The IAEA and the Absolute Weapon. Washington, D.C.: Georgetown University Press.

Chumley, Lily Hope

2017 "Qualia and Ontology: Language, Semiotics, and Materiality; an Introduction." Signs and Society 5, no. S1: S1-S20. https://doi.org/10.1086/690190.

Collon, Dominique, ed.

19977000 Years of Seals. London: British Museum Press.

Du Bois, John W.

1993 "Meaning without Intention: Lessons from Divination." In Responsibility and Evidence in Oral Discourse, edited by Jane H. Hill and Judith T. Irvine, 48-71. Cambridge, UK: Cambridge University Press.

Duistermaat, K., I. Regulski, and P. Verkinderen, eds.

2012 Seals and Sealing Practices in the Near East: Developments in Administration and Magic from Prehistory to the Islamic Period. Proceedings of an International Workshop at the Netherlands-Flemish Institute in Cairo on December 2-3, 2009. Leuven, Belgium: Peeters.

ElBaradei, Mohamed

2011 The Age of Deception: Nuclear Diplomacy in Treacherous Times. New York: Henry Holt.

Fathi, Nazila, and Thomas Fuller

2005 "Iran Removes Seals on Equipment at Nuclear Plant." New York Times, August 10.

Forland, Astrid

1997 "Negotiating Supranational Rules: The Genesis of the International Atomic Energy Agency Safeguards System.” PhD diss., University of Bergen.

Fuller, Thomas, and Nazila Fathi

2005 "U.N. Agency Urges Iran to Halt Its Nuclear Activity.” New York Times, August 12.

Gal, Susan

2017 "Qualia as Value and Knowledge: Histories of European Porcelain.” Signs and Society 5, no. S1: S128-S153. https://doi.org/10.1086/690108.

Gerami, Nima, and Pierre Goldschmidt

2012 "The International Atomic Energy Agency's Decision to Find Iran in NonCompliance, 2002-2006." Case Study 6. Washington, D.C.: National Defense University Press.

Gibson, McGuire, and Robert D. Biggs, eds.

1977 Seals and Sealing in the Ancient Near East. Malibu, Calif.: Undena Publications.

Goddard, Braden, Alexander Solodov, and Vitaly Fedchenko

2016 “IAEA 'Significant Quantity' Values: Time for a Closer Look?” Nonproliferation

Grice, H. Paul Review 23, nos. 5-6: 677-89. https://doi.org/10.1080/10736700.2017.1339934.

1957 “Meaning." Philosophical Review 66, no. 3: 377-88. https://doi.org/10.2307/ 2182440.

Hamblin, Jacob Darwin

2016 “'A Glaring Defect in the System': Nuclear Safeguards and the Invisibility of Technology." In Negotiating the Nuclear Non-Proliferation Treaty: Origins of the Nuclear Order, edited by Roland Popp, Liviu Horovitz, and Andreas Wenger, 203 19. New York: Routledge. 
Hecht, Gabrielle

2007 “A Cosmogram for Nuclear Things.” Isis 98, no. 1: 100-108. https://doi.org/10. 1086/512834.

2012 Being Nuclear: Africans and the Global Uranium Trade. Cambridge, Mass.: MIT Press. Hill, Jane H., and Judith T. Irvine, eds.

1993 Responsibility and Evidence in Oral Discourse. Cambridge, UK: Cambridge University Press.

Holloway, David

2016 "The Soviet Union and the Creation of the International Atomic Energy Agency." Cold War History 16, no. 2: 177-93. https://doi.org/10.1080/14682745.2015.1124 265.

Holloway, David, and Leopoldo Nuti

2018 "Introduction." In "Aspects of the Global Nuclear Order in the 1970s," special issue, International History Review 40, no. 5: 963-64. https://doi.org/10.1080/070 75332.2018.1432497.

Hull, Matthew S.

2012 Government of Paper: The Materiality of Bureaucracy in Urban Pakistan. Berkeley: University of California Press.

IAEA (International Atomic Energy Agency)

1956 "IAEA Statute." Vienna: IAEA.

2005 "Communication Dated 1 August 2005 Received from the Permanent Mission of the Islamic Republic of Iran to the Agency." Information Circular INFCIRC/648. Vienna: IAEA.

IAEA (International Atomic Energy Agency) and Board of Governors

2004 "Implementation of the NPT Safeguards Agreement in the Islamic Republic of Iran: Report by the Director General.” GOV/2004/83. Vienna: IAEA.

2005a "Implementation of the NPT Safeguards Agreement in the Islamic Republic of Iran and Related Board Resolutions: Resolution Adopted on 11 August 2005.” GOV/2005/64. Vienna: IAEA.

2005b "Implementation of the NPT Safeguards Agreement in the Islamic Republic of Iran: Resolution Adopted on 24 September 2005.” GOV/2005/77. Vienna: IAEA.

2006 "Implementation of the NPT Safeguards Agreement in the Islamic Republic of Iran: Resolution Adopted on 4 February 2006." GOV/2006/14. Vienna: IAEA.

Inoue, Miyako

2018 "Word for Word: Verbatim as Political Technologies.” Annual Review of Anthropology 47: 217-32. https://doi.org/10.1146/annurev-anthro-102116-041654.

Johnston, Roger G.

2001 "Tamper Detection for Safeguards and Treaty Monitoring: Fantasies, Realities, and Potentials." Nonproliferation Review 8, no. 1: 102-15. https://www.nonproliferation.

Keane, Webb org/research/nonproliferation-review/npr-8-1/.

2003 "Semiotics and the Social Analysis of Material Things." Language and Communication 23, nos. 3-4: 409-25. https://doi.org/10.1016/S0271-5309(03)00010-7.

2007 Christian Moderns: Freedom and Fetish in the Mission Encounter. Berkeley: University of California Press.

Kockelman, Paul

2006 "Agent, Person, Subject, Self." Semiotica 2006, no. 162: 1-18. https://doi. org/10.1515/SEM.2006.072.

2007 "Agency: The Relation between Meaning, Power, and Knowledge." Current Anthropology 48, no. 3: 375-401. https://doi.org/10.1086/512998.

2013 Agent, Person, Subject, Self: A Theory of Ontology, Interaction, and Infrastructure. Oxford: Oxford University Press. 
Larkin, Brian

2018 "Promising Forms: The Political Aesthetics of Infrastructure." In The Promise of Infrastructure, edited by Nikhil Anand, Akhil Gupta, and Hannah Appel, 175-202. Durham, N.C.: Duke University Press Books.

Latour, Bruno

1992 "Where Are the Missing Masses? The Sociology of a Few Mundane Artifacts." In Shaping Technology/Building Society: Studies in Sociotechnical Change, edited by Wiebe E. Bijker and John Law, 225-58. Cambridge, Mass.: MIT Press.

1999 Pandora's Hope: Essays on the Reality of Science Studies. Cambridge, Mass.: Harvard University Press.

2000 "The Berlin Key or How to Do Words with Things." In Matter, Materiality, and Modern Culture, edited by Paul Graves-Brown, 10-21. London: Routledge.

Law, John, and Annemarie Mol

1995 "Notes on Materiality and Sociality." Sociological Review 43, no. 2: 274-94. https:// doi.org/10.1111/j.1467-954X.1995.tb00604.x.

Lewis, Jeffrey

2006 "NCRI Did Not Discover Natanz." Arms Control Wonk, October 28. https://www. armscontrolwonk.com/archive/201274/ncri-did-not-discover-natanz/.

2007 “NCRI Still Didn't Discover Natanz." Arms Control Wonk, December 12. https:// www.armscontrolwonk.com/archive/201737/ncri-still-didnt-discover-natanz/.

Lynch, Michael, Simon A. Cole, Ruth McNally, and Kathleen Jordan

2008 Truth Machine: The Contentious History of DNA Fingerprinting. Chicago: University of Chicago Press.

Magness-Gardiner, Bonnie

1997 "Seals." In The Oxford Encyclopedia of Archaeology in the Near East, edited by Eric M. Meyers. Oxford Biblical Studies Online. http://www.oxfordbiblicalstudies.com/ article/opr/t256/e948.

Mallard, Grégoire

2014 Fallout: Nuclear Diplomacy in an Age of Global Fracture. Chicago: University of Chicago Press.

Obama, Barack

2015 "The President Announces a Historic Nuclear Deal with Iran.” YouTube video, 13:10. Posted by TheObamaWhiteHouse, July 14. https://www.youtube.com/ watch? $\mathrm{v}=$ OLhV3JRWKUM.

Ong, Aihwa, and Stephen J. Collier, eds.

2005 Global Assemblages: Technology, Politics, and Ethics as Anthropological Problems. Malden, Mass.: Blackwell.

Pouliot, Vincent

2010 "The Materials of Practice: Nuclear Warheads, Rhetorical Commonplaces and Committee Meetings in Russian-Atlantic Relations." Cooperation and Conflict 45,

Richland, Justin B. no. 3: 294-311. https://doi.org/10.1177/0010836710377487.

2006 “The Multiple Calculi of Meaning." Discourse and Society 17, no. 1: 65-97. https:// doi.org/10.1177/0957926505056672.

Robbins, Joel, and Alan Rumsey

2008 "Introduction: Cultural and Linguistic Anthropology and the Opacity of Other Minds." Anthropological Quarterly 81, no. 2: 407-20. https://doi.org/10.1353/anq. 0.0005 .

Roehrlich, Elisabeth

2016 "The Cold War, the Developing World, and the Creation of the International Atomic Energy Agency (IAEA), 1953-1957.” Cold War History 16, no. 2: 195-212. https://doi.org/10.1080/14682745.2015.1129607.

2018 "Negotiating Verification: International Diplomacy and the Evolution of Nuclear Safeguards, 1945-1972.” Diplomacy and Statecraft 29, no. 1: 29-50. https://doi.org /10.1080/09592296.2017.1420520. 
Scheinman, Lawrence

1987 The International Atomic Energy Agency and World Nuclear Order. Washington, D.C.: Resources for the Future Press.

Shaker, Mohamed I.

1980 The Nuclear Non-Proliferation Treaty: Origin and Implementation, 1959-1979. London: Oceana Publications.

Sidnell, Jack

2017 "Distributed Agency and Action under the Radar of Accountability." In Distributed Agency, edited by N. J. Enfield and Paul Kockelman, 87-96. New York: Oxford

Silverstein, Michael University Press.

2003 “Translation, Transduction, Transformation: Skating 'Glossando' on Thin Semiotic Ice." In Translating Cultures: Perspectives on Translation and Anthropology, edited by Paula G. Rubel and Abraham Rosman, 75-105. Oxford: Berg.

Star, Susan Leigh, and Martha Lampland

2009 "Reckoning with Standards." In Standards and Their Stories: How Quantifying, Classifying, and Formalizing Practices Shape Everyday Life, edited by Martha Lampland and Susan Leigh Star, 3-24. Ithaca, N.Y.: Cornell University Press.

Traynor, Ian, and Ewen MacAskill

2005 "Iran Risks Showdown as Work at Atomic Site Resumes." Guardian (UK), August 8. von Schnitzler, Antina

2013 "Traveling Technologies: Infrastructure, Ethical Regimes, and the Materiality of Politics in South Africa." Cultural Anthropology 28, no. 4: 670-93. https://doi. $\operatorname{org} / 10.1111 /$ cuan.12032.

Weichselbraun, Anna Maria

2016 "Constituting the International Nuclear Order: Bureaucratic Objectivity at the IAEA.” PhD diss., University of Chicago.

Weisman, Steven R.

2005 “Offer by Europe Would Give Iran Nuclear Future.” New York Times, August 5.

Wengrow, David

2008 "Prehistories of Commodity Branding." Current Anthropology 49, no. 1: 7-34. https://doi.org/10.1086/523676. 